\title{
Puchos y cucarachas El estatuto de lo residual en la subjetividad y la política
}

\section{Stubs and cockroachs}

The status of the residual in subjectivity and politics

\section{Eduardo Rinesi}

\section{RESUMEN:}

Para pensar el carácter insanablemente conflictivo que tiene la vida de los hombres y de los pueblos vale la pena utilizar el recurso a los grandes géneros de la literatura dramática: la comedia y sobre todo la tragedia. Para pensar el lugar de lo residual (de lo que sobra y de lo que se expulsa) de esas vidas individuales y colectivas puede ser útil apelar a dos categorías que se encuentran en distintos sitios en las obras de Freud y de Lacan, y que acaso tengan un servicio que prestar a la filosofía política y social: la de resto y la de desecho. La discusión sobre la relación que puede establecerse entre los distintos tipos de tragedia y la pertinencia analítica de una u otra de estas dos categorías puede verse enriquecida por una consideración sobre lo que los hombres hacemos, en nuestras grandes ciudades contemporáneas, con la basura que producimos y de la que, a través de distintos procedimientos y tecnologías, intentamos deshacernos.

Palabras Clave:

Tragedia - restos - desechos - duelo hegemonía

\section{SUMMARY:}

In order to think about the unhealthily conflictive character which falls upon men's and peoples lives, it is worth to turn on the great genres of literary drama: comedy and especially tragedy. For the place of the residual (the remaining and the removed) in those individual and colective lives, it would be worth to have recourse to two categories to be found in different points of Freuds and Lacan works because it is probable that both authors could contribute to social and political philosophy: that one of the rest and the débris. The discussion about the posible relation between different types of tragedies and the analitical pertinence of each categories, can be enriched by a consideration about what men do, in our immense contemporary cities, with the garbage we produce and how we try to take it out of our lives using different procedures and technologies.

\section{KEY WORDS:}

Tragedy - rest - remainders - sorrow hegemony 

La tragedia y la comedia constituyen sugerentes instrumentos conceptuales para pensar la vida de los hombres y los pueblos porque laboran con una materia fundamental para la comprensión de esas vidas individuales y colectivas que es el conflicto. Que a veces es el conflicto entre dos sistemas de dioses, de valores o de principios que pueden dividir una comunidad (como en Antígona) o disputarse el corazón atormentado de un sujeto (como en Hamlet), y que otras veces es el conflicto entre las condiciones para la realización de la ciudad y las que reclama la realización de alguno o de algunos, o eventualmente de todos, los sujetos que la integran (como en El mercader de Venecia). Para no andar dando saltos mortales por los siglos, limitaré la comparación que querría presentar acá a la que puede establecerse entre las dos piezas de Shakespeare que quedan mencionadas: la tragedia del melancólico príncipe danés y la rara "comedia" (que en su interior encierra, como en un juego de muñecas rusas, una tragedia atroz) del comerciante homosexual, el prestamista judío y los jóvenes heterosexuales y cristianos y bellos y exitosos y crueles que los humillan y destrozan a ambos en El mercader... Trataremos de pensar, alrededor de esas dos piezas mayores de la dramaturgia shakespeareana, los significados y la pertinencia del uso de las categorías de "resto" y de "desecho", y después trataremos de darle otra vuelta de tuerca al cotejo entre estas dos categorías a partir del análisis de un libro reciente sobre cuestiones de antropología urbana, que nos enseña unas cuantas cosas, me parece, sobre el carácter nada residual del problema de los residuos en la vida contemporánea.
I.

En Hamlet, el protagonista se encuentra solicitado simultáneamente por dos sistemas de valores encontrados: uno, al que podemos llamar guerrero, medieval, o quizás sólo paterno, lo manda tomar la vida de su tío en venganza por el crimen que éste cometió; el otro, al que podemos llamar civil, burgués, o quizás sólo moderno, lo manda no andar matando gente por ahí. Tironeado entre esas dos exigencias morales contrapuestas, lo que hace el vacilante Hamlet, como sabemos bien, es no hacer nada: no actúa, demora, procastina, y sólo cumple la orden de su padre al final, al final de todo, incluida dentro de ese "todo" su propia vida, porque Hamlet sólo se decide a atravesar con su espada el cuerpo de su tío cuando se entera de que él mismo está a punto de morir. Cuando esto finalmente ocurra, Hamlet se despedirá con una frase muy famosa, su célebre "The rest is silence" (5.2.337), que repone sobre el final de la pieza una palabrita que había aparecido en el inicio, cuando el príncipe recibe la visita y el mandato del espectro de su padre y lo despide (no sin antes haberle preguntado por qué demonios había salido de su tumba en lugar de quedarse en ella, donde todos lo creían y lo querían encerrado para siempre) diciéndole que se quede tranquilo, que se quede quieto y que descanse: "Rest, rest, perturbèd spirit” ( ( .5.I83).

Así, Hamlet transcurre entre el "Rest, rest...” (rest: descansá) del comienzo y el "The rest is silence" (rest: resto) del final, y no sería inexacto sostener que lo hace hablando exactamente, y siempre, todo el tiempo, sobre eso: sobre el resto y los restos y el restar (restar: quedarse, descan- 
sar, quedarse en un lugar y no moverse, no rondar, que es lo que hacen los espectros, que justo por eso nos angustian), todo a lo largo de la pieza. Incluso después de que el propio príncipe haya muerto con esa frase sobre el resto del tiempo, que para él será silencio, cuando aparezca el joven Fortimbrás, futuro rey de Dinamarca, y después de haber entendido qué fue lo que pasó ordene sepultar a Hamlet, garantizar las condiciones para que todo el reino pueda hacer el correspondiente y necesario travail du deuil por la muerte del muchacho y después enterrarlo bien profundo, para que, como explica Derrida jugando con las palabras en francés, "dans ce qui rest de lui, il y rest": para que, en lo que queda de él, en sus restos, él se quede allí, descanse (rest) en paz, y no quiera resurgir del más allá, volver del más allá, como en cambio su papá, mal enterrado y mal llorado (esto Lacan lo vio muy bien), hacía todo el tiempo, para seguir incordiando en el mundo de los vivos.

Por supuesto, esta pretensión, este sueño, es imposible. Por supuesto, los muertos nunca se quedan quietecitos en sus tumbas. Por supuesto, el pasado vuelve todo el tiempo, porque el tiempo está siempre, constitutivamente, out of joint, fuera de quicio. Por eso es que hay tragedia: por eso es que el mundo y que la vida son trágicos. Hay tragedia, y el mundo y la vida son una tragedia, porque los muertos no se quedan quietos, porque el pasado no queda, no se queda, en el pasado. Que es como decir: porque el tiempo nunca es contemporáneo de sí mismo, porque el presente está siempre habitado por los restos (rests) del pasado que se resisten a desaparecer, porque los restos de las cosas, de las personas, de las épocas que van quedando atrás, y que querríamos sepultadas para siempre, vuelven, siempre, por sus fueros. Hamlet es una tragedia sobre los restos que nos ayuda a comprender que los restos no son nunca cosa del pasado: que los restos son restos actuando, insistiendo, perseverando siempre en el presente, que los restos nunca descansan, nunca se resignan a pasar el resto de la eternidad descansando y en silencio. Que el destino mismo de los restos es volver, es estar siempre volviendo.

A diferencia de Hamlet, El mercader... no se presenta como una tragedia sino como una comedia, y esa presentación no es inadecuada, aunque no debería impedirnos ver todo lo tremendo que se esconde bajo el aparente "final feliz" de una historia en la que, en efecto, a diferencia de lo que ocurre en las tragedias, nadie muere, en la que todo el mundo parece poder ser aceptado sin conflictos en el seno del orden colectivo, y en la que en particular los dos protagonistas principales de la pieza, los dos "viejos" de la pieza: el viejo mercader homosexual que había amenazado con su amor la felicidad conyugal (el sistema de exclusión de cierta forma del deseo) de su amigo Basanio y de la bella Porcia y el viejo prestamista judío que había amenazado con su pretensión justiciera la felicidad colectiva (el sistema de exclusiones sobre el que se sostiene la res publica) de Venecia, son recibidos de vuelta en el seno de esos dos órdenes, el de los afectos y el de la polis, a cambio apenas de lo que quienes imponen sus condiciones a los vencidos (al judío, vencido por la mayoría cristiana de la ciudad en su procura de justicia, al mercader, vencido por Porcia en su lucha por el corazón de su antiguo amante) presentan como un precio módico a pagar: Shylock debe renunciar, apenas, a su identidad judía, a su fortuna y a su hija; Antonio, apenas, a Basanio. 
El problema es ese “apenas”. El problema es qué queda de Shylock cuando a Shylock se le exige renunciar a algo tan constitutivo de su propia identidad como su condición judía, su fortuna y su hija; el problema es qué queda de Antonio cuando a Antonio se le exige resignar algo tan importante para él como el amor que siente por su amigo. El problema es qué queda de los sujetos cuando a esos sujetos se les cobra, como cuota de ingreso o de re-ingreso a la vida social, una "libra de carne" tan decisiva que los deja necesariamente por debajo de sus expectativas de realización plena; qué queda de los sujetos después de la entrega de esa libra de carne que los deja des-hechos: desechos. Pero ¿no es éste siempre, el caso? ¿Vivir en sociedad no es siempre aceptar un contrato por el que entregamos una libra de carne de nosotros mismos a cambio de la posibilidad de un ingreso (formalmente irrestricto, pero que sólo puede consumarse a condición y al costo de esa mutilación, de esa quita, de ese corte) a un orden social que nunca nos puede recibir enteros, que por mucho que se presente y que se re-presente como perfectamente plural e inclusivo es siempre menos que la imposible suma de sus partes?

En El mercader..., ni el usurero judío ni el comerciante homosexual son asesinados: ninguno de los dos muere. Ninguno muere porque sería inaceptable que fueran sacados del camino de ese modo, mandados a descansar (rest) bajo tierra, porque eso sería reconocer que la ciudad en la que vivían no podía tolerarlos. Y no: Venecia sí puede tolerarlos -se dice Venecia a sí misma-. Y debe tolerarlos. Entre otros motivos porque las cosas se le volverían mucho más difíciles si, por no hacerlo, los mandara a matar y a enterrar y tuviera después que soportar que esos muertos injustamente asesinados volvieran como espectros a denunciar, como el del papá de Hamlet, la injusticia de ese crimen. No: Venecia puede sostenerse sin matar a nadie (se dice Venecia a sí misma), porque es una república plural y respetuosa. Y por eso les perdona la vida a Antonio y a Shylock, pero es solo eso (la vida, la pura vida, nada más que la vida) lo que les perdona. Les perdona la vida pero les arranca a esas vidas perdonadas lo que las hacía diferentes, desecha de esas vidas su particularidad irreductible, que es lo que la ciudad no puede tolerar, y las vuelve, así, desechos. Vivir en sociedad es siempre (me parece que ésa es la enseñanza última de El mercader...) haber aceptado vivir como desecho.

No sé adónde puedan conducirnos estas elucubraciones, aunque tengo la impresión de que no es poco lo que pueden servir a nuestras consideraciones sobre las vidas individuales y sobre la vida política y social estas dos categorías de los restos y de los desechos, y por eso puede ser útil hacer sobre ellas algunas precisiones. La primera es que ni una ni otra aluden a "cosas" o a dimensiones objetivas de nuestros intercambios que puedan identificarse y designarse nítidamente con una de esas dos categorías o con la otra: no hay restos ni desechos "objetivos". Si tuviera que decirlo de un modo muy rápido, diría que resto es cualquier dimensión inasimilable de un orden cualquiera, que como es inasimilable nos sacamos de encima para que ese orden -como suele decirse- "cierre", pero que no podemos evitar que se quede ahí (restar: quedarse), y que se quede insistiendo, asediándonos, volviendo todo el tiempo, que se quede perseverando, que se quede como una sombra o una promesa o 
una amenaza o una obstinación. Análogamente, me parece importante señalar ahora que, en el modo en el que estoy usando aquí la idea de desecho, la misma no se refiere (o no se refiere solamente) a "eso", a ese exceso o esa sobra que el sujeto debe desechar de sí para poder vivir en sociedad, sino a lo que queda de ese mismo sujeto después de que desechó de sí, después de que apartó o descartó esa demasía que no le era tolerada. Para volver sobre la famosa y potente imagen de la "libra de carne": no es la libra de carne el desecho: el desecho es lo que queda del sujeto después de que éste aceptó esa mutilación. ¿No es lo que nos enseña Freud en El malestar en la cultura: que vivir en sociedad es haber renunciado a la felicidad? Primera conclusión.

Y la segunda: que ningún orden puede cobijar las distintas partes que lo integran sin haber desechado algo de ellas y sin haberlas vuelto a ellas, a través de este movimiento, un desecho. Todo orden contiene a las partes que lo constituyen, pero las contiene mutiladas, castradas. Todo universal se funda en un acto de exclusión. Lo que aquí estoy sugiriendo es que "eso" que todo universal excluye, que toda sociedad desecha, no es necesariamente una persona o un grupo de personas. Es más bien un cierto algo de intolerable y de inaceptable, que en El mercader... se presenta bajo la figura de esa "libra de carne", que es, además de una metáfora evidente -en una pieza que trata de cristianos y judíos y de sus luchas y de su mutuo afán de convertirse mutuamente- de la circuncisión, una metáfora más general de esa verdadera circuncisión que toda sociedad exige siempre a todos aquellos a los que recibe. Insisto: no es que ningún orden social permita la realización plena de todas sus partes, sino que ningún orden social permite la realización plena de ninguna de sus partes, porque todas y cada una de ellas deben aceptar, como precio por su inclusión en ese todo, el desecho de una dimensión o de una arista de sí misma y la condición de ser recibida en ese orden, ella misma, como un desecho.

\section{II}

Hemos sugerido hasta aquí tres cosas. Una, que es posible identificar dos grandes tipos de tragedia: la tragedia de la contraposición entre sistemas de valores enfrentados (de la que tomamos como ejemplo Hamlet) y la tragedia de la contraposición entre el todo y la imposible suma de sus partes (que ejemplificamos con El mercader...). Otra, que es posible tratar de aprovechar, para el análisis de los problemas de la vida colectiva, dos categorías que aparecen aquí y allá en algunos textos de Freud y de Lacan (y no sólo allí, por cierto, aunque un estudio más minucioso de esas apariciones y de las variaciones en los sentidos que adoptan en uno y otro, en sus distintos textos y eventualmente en los distintos momentos de sus obras, podría resultar muy útil) de los restos y de los desechos. Y la tercera, que es posible postular (siquiera como una hipótesis intencionalmente simplificadora) una especie de correspondencia biunívoca entre estos dos pares que acabo de presentar: a la tragedia de la contraposición entre sistemas de valores enfrentados le "correspondería" -digamos así- una lógica del resto; a la de la contraposición entre el todo y la imposible suma de sus partes, una de los desechos.

No se me escapa que todo esto es extremadamente esquemático: ya habrá tiempo de complejizar un poco todo el asunto, y le prometo al lector que no tendrá que 
esperar para ello más que unos pocos párrafos. Pero permítaseme ahora aprovechar el envión para dar un pasito más y decir dos cosas muy rápidas. La primera es que me parece que puede sostenerse que lo que arriba bauticé como la lógica del resto, y puse en comunicación con lo que llamé la tragedia de la contraposición entre sistemas de valores enfrentados, nos da una clave de acceso al problema filosófico fundamental del tiempo: del tiempo histórico, mientras que lo que arriba bauticé como la lógica de los desechos, y puse en comunicación con lo que llamé la tragedia de la contraposición entre el todo y la imposible suma de sus partes, nos ofrece una puerta de entrada al problema, complementario pero diferente, del espacio: del espacio social. La segunda es que el primer conjunto de asuntos que quedan definidos alrededor de la lógica del resto y del problema del tiempo nos conduce, dentro del campo de la filosofía política contemporánea, a la obra de Jacques Derrida, mientras que el segundo conjunto de problemas que quedan circunscriptos alrededor de la lógica de los desechos y del problema del espacio nos lleva al pensamiento de Jacques Rancière.

Resto y tiempo, entonces. Porque lo que resta, lo que queda, queda sepultado mientras la historia pasa y porque la historia pasa y para que la historia pase, pero después vuelve para cobrarse su revancha llegando desde ese pasado que, como suele decirse, "creíamos superado", desestabilizando el presente, desquiciando el tiempo. En su muy celebrado y muy importante Espectros de Marx, Derrida estudia esta forma de presencia del pasado en el presente, de los muertos en medio de los vivos, tomando como referencia a Hamlet, por supuesto, pero también al
Dieciocho Brumario, al que ya aludimos también nosotros más arriba. Desechos $y$ espacio. Porque no hay orden político que no suponga una cierta organización, una cierta distribución de los lugares que en él pueden o deben ocupar las distintas partes que lo integran, que lo com-parten (Rancière juega en francés con la doble valencia de partager: compartir y también dividir: estamos en el campo, bien se ve, de una reflexión sobre el espacio, sobre los lugares), pero que nunca se adecuan a él sin todo tipo de incomodidades ni terminan de ingresar a él sin someterse, como ya dijimos, a la amputación de esa "libra de carne" de sí mismas que tienen que sacrificar en el altar del orden y que las deja, como por debajo de sus propias posibilidades, des-hechas.

Esta doble constatación de que nunca el presente es contemporáneo de sí mismo y de que nunca el todo es igual a la suma de sus partes, de que el tiempo y el espacio están, ambos, "fuera de quicio", es fundamental para entender la naturaleza misma de eso a lo que damos el nombre de política, que no es otra cosa que el conjunto de actividades a través de las cuales los hombres lidiamos con ese doble desquicio, con esa doble inadecuación. El siglo xx pensó esta tarea bajo el signo de lo que llamó hegemonía, que de Gramsci para acá designa el doble movimiento de construir un orden en medio y a pesar de ese desquicio, de ese desorden del tiempo y del espacio, de ese estar todo el tiempo volviendo de los espectros que llegan del pasado y de ese estar todo el tiempo sobrando de las distintas partes que en su suma siempre conflictiva, siempre imposible, componen el "todo" de una sociedad. Un todo que por lo tanto no cesa de instituirse, de manera siempre precaria, en lo que Ernesto 
Laclau, sin duda influido por la idea freudiana, homóloga a ésta, de "trabajo del duelo", llamó un "trabajo": el "trabajo de la hegemonía”, que es siempre una operación, necesariamente incompleta, necesariamente fallida, sobre el doble eje del tiempo histórico (y del trabajo, por lo tanto, sobre los restos) y del espacio social (y del trabajo, entonces, sobre los desechos).

¿Pero se trata en efecto de dos ejes distintos, o la distinción que puede hacerse entre ellos es apenas analítica, o incluso más: formal? ¿Es seguro que podamos distinguir tan nítidamente como hasta aquí venimos haciéndolo en un plano puramente conceptual entre "restos" y "desechos", como si fueran "cosas" (dijimos ya que no lo son) objetivamente diferentes? ¿No deberíamos en cambio estar atentos a las posibilidades de transformación o de transposición entre restos y desechos, de restos en desechos o al revés? Las lógicas del "resto" y del “desecho", ¿no definen más bien posibilidades que es siempre $u n$ sujeto, en su relación con aquello que puede presentársele bajo una de esas figuras o bajo la otra, el que realiza? La misma duda corresponde formular en relación con la posibilidad de distinguir lo que, abusando quizás de dos figuras necesariamente simplificadoras y estilizadoras de situaciones mucho más complejas, llamamos más arriba "espacio" y "tiempo": ¿no es obvio que en el juego político y en el devenir mismo de la historia se redefinen permanentemente (más: que la lucha politica es entre otras cosas la lucha por esa redefinición) los frágiles límites entre lo que nombramos con cada una de esas dos metáforas?
III

La palabra "basura", o la un poco más sofisticada "residuos", nombra el conjunto de desperdicios, de sobras, de despojos que producimos los hombres viviendo en sociedad, y que adquiere las características de un problema a veces muy serio en los grandes centros urbanos donde esa vida de los hombres en común tiende cada vez más a organizarse. En un libro extraordinario sobre el problema de la relación entre sociedad y residuos en la ciudad de Buenos Aires, Francisco Suárez ofrece un conjunto de orientaciones del mayor interés para pensar los problemas que hemos planteado más arriba, esbozando alrededor de la idea de los residuos, de la basura (de esos restos y de esos desechos que son la basura de la que los habitantes de nuestras ciudades nos desprendemos día a día, y con la que no dejamos, antes y después de desprendernos de ella, de convivir), una poderosa teoría sobre la vida urbana, o quizás, más en general, sobre la vida colectiva sin más.

Suárez parte de constatar que en Buenos Aires (pero lo mismo podría decirse con seguridad de casi todos los grandes centros urbanos del planeta) "no hay lugar para lo que se desecha”, y estudia en una perspectiva histórica los modos en los que la ciudad, a lo largo de los siglos (sobre todo de los últimos dos, y especialmente del último), "gestionó" este exceso, este sobrante de lo que se descarta respecto al lugar con el que la propia ciudad cuenta para descartarlo. En su presentación de la historia de estos procedimientos (desde las zanjas de la época colonial hasta las incineraciones y los rellenos sanitarios de tiempos más recientes), Suárez señala la importancia del establecimiento de los basurales, sitios de disposición y distribu- 
ción de los residuos que se volverán una presencia fundamental en la cultura de los márgenes (geográficos y sociales) de nuestra vida urbana, en el surgimiento y expansión de las actividades de "recuperación" de esos residuos, o "cirujeo" (cuya progresiva complejización funcional irá definiendo con los años distintas figuras, como las del "recuperador", el "clasificador", el “custodio"...), en el desarrollo de prácticas productivas como la crianza de cerdos, en el asentamiento de "villas miseria" cuya economía y sociabilidad estaban y están fuertemente asociadas al aprovechamiento de la basura, y en expresiones culturales típicas como la literatura y el tango.

Un capítulo tardío de esta historia es el que corresponde a la actividad de los llamados "cartoneros", que a fin del siglo pasado empiezan a ser una presencia muy visible e importante en la vida de la ciudad, dando lugar, entre otras muchas cosas, al fenómeno de su organización cooperativa, muy significativa durante los primeros lustros del corriente siglo. Suárez recuerda una imponente marcha, en marzo de 20I5, de más de 2000 cartoneros, movilizados bajo la consigna "Somos lo que falta". Desde 2003, de la mano de una recuperación de las grandes variables de la economía del país, muchos sectores sociales habían logrado incluirse dentro de un orden social mucho menos hostil que el que había caracterizado el fin del siglo anterior. Pero los cartoneros todavía padecían una situación de mucha marginación, y reclamaban más ayuda estatal y mejores condiciones para la formalización de su trabajo. El "Somos lo que falta" aludía exactamente a eso: la economía mejora, otros sectores (el del trabajo formal, el de los trabajadores pasivos, el de los trabaja- dores desocupados) gozan de más beneficios que antes, pero nosotros estamos más o menos como siempre: faltamos nosotros.

La expresión no podría ser, desde el punto de vista de lo que acá estamos estudiando, más interesante, porque desde otra perspectiva lo que sería fácil observar es que estos recuperadores urbanos, trabajadores precarios que viven de lo que otros tiran, de lo que a la ciudad le sobra, de las sobras, son ellos mismos, en un sentido muy preciso, lo que sobra, más que lo que falta. Lo que sobra y no puede ser asimilado como sería deseable que lo fuera por las estructuras de una economía formal que siempre deja gente afuera. $\mathrm{O}$ adentro, pero por debajo de las posibilidades de realización plena, cabal, que legítimamente querrían ver materializada. De manera que ellos, los que sobraban, gritaban que eran lo que faltaba: ellos, las sobras, decían que su presencia ahí era la falta del sistema al que le reclamaban una inclusión más plena. Estamos en el corazón de lo que más arriba llamé "la lógica del desecho": vivir en sociedad es siempre (no para todos en igual medida, porque las sociedades son desiguales e injustas, pero siempre) vivir por debajo de las posibilidades de esa inclusión plena que querríamos y que demandamos. Vivir en sociedad es siempre vivir como una sobra y vivir en falta.

¿No es esta dialéctica de la sobra y de la falta la que está en el corazón de la figura de la "libra de carne" que introduce Shakespeare en El Mercader...? ¿No es al mismo tiempo esa libra de carne -que Marx, recordemos, usaba como metáfora o figura de la plus-valía: la libra de carne que se saca como metáfora del valor que sobra-, no es al mismo tiempo esa libra de carne, digo, lo que falta $y$ lo que sobra? 
¿No es la lógica que gobierna el lugar de esa libra de carne la lógica de la castración y también la del exceso? "Somos lo que falta": somos lo que falta hacer entrar, porque somos lo que sobra de un sistema que no puede darnos esa entrada que le reclamamos. O que no puede darnos esa entrada plenamente. Por eso viviremos por debajo de nuestras posibilidades, por debajo de nosotros mismos. Faltamos. Es decir: sobramos. Somos sobras. Desechos. Puchos. En una novela de Julián Centeya, El vaciadero, inspirada en la vida en torno al basural del Bajo Flores, que Suárez cita y comenta en su trabajo, leemos de una manera muy precisa la lógica exacta del desecho: "Todos somos pucho de algo..." Igual de preciso, Juan Sasturain comienza uno de sus poemas escribiendo "Soy lo que queda / de mí". Vivir, ser, es ser lo que queda de nosotros después de que ese "nosotros" se nos reveló imposible.

¿Y nada más? No: nada más no, porque eso que descartamos, que desechamos de nosotros, esa libra de carne de la que aceptamos desprendernos para que la vida social y nuestra propia vida sean posibles, esas sobras (esos que sobran) de la vida colectiva que la sociedad deja en sus suburbios porque no puede incorporar a sus barrios centrales, no se quedan en esos arrabales sin volver sobre esos barrios centrales todo el tiempo, sin aparecer de vuelta en esos barrios centrales que los expulsaron y los dejaron al costado. En efecto, ¿no tenían algo de espectrales esas presencias de grupos o cuadrillas de cartoneros que desde fines de los años 90 del siglo pasado volvían al centro de la ciudad, desde las zonas más pobres de su periferia, como rondando, asediando, acechando, angustiando a los habitantes de ese centro (rondar, asediar, acechar, an- gustiar: significados del "hanter" de los fantasmas del que nos habla Derrida en el libro que ya hemos mencionado) con su presencia inquietante, fantasmagórica, nocturnal...? Pero incluso antes que eso, ¿podemos olvidar, cuando pensamos en la figura de los basurales, del basural, en la historia política argentina, podemos olvidar, digo, a aquel "fusilado que vive" $y$ que vuelve, como un espectro, como un mensajero del mundo de los muertos que trae al de los vivos, desde el sumidero del que llega y donde sus compañeros han sido asesinados, un mensaje sobre lo que pasó, en el comienzo de Operación Masacre de Rodolfo Walsh?

¿Y qué decir si no, también, de esas otras presencias fantasmales que llegan, después de la muerte, de los basurales de los que nos hablan, por ejemplo, las crónicas policiales sobre el asesinato de la joven Ángeles Rawson, “descubierta” en medio de la basura por recuperadores de residuos que cumplían con su tarea de inspeccionarlos y separarlos? Fue muy comentado este caso atroz de femicidio, al que la circunstancia de que el cadáver de la chica asesinada fuera encontrado entre la basura agregaba un plus de significación tan ominoso como importante para lo que aquí estamos tratando de plantear. Una nota periodística sobre el asunto, que Suárez recuerda en su libro, se había titulado, en su momento, “Ángeles Rawson murió como lo que era: una basura”, y no puede dejar de alertarnos el valor de esta palabra y la frecuencia de su uso para nombrar, por un efecto de deslizamiento más o menos evidente, no ya apenas a los residuos que los habitantes de las ciudades producimos y para los cuales, como decíamos un poco más arriba, "no hay lugar", sino también a las personas o los grupos 
de personas que esas mismas ciudades no dejan de excluir, de separar, de marginar, y para las cuales tampoco "hay lugar". Parte de los "sin parte", para usar la fórmula, aquí muy pertinente, de Rancière, esas personas o esos grupos de personas también son residuos de una sociedad que los produce y no los puede contener.

Peter Stallybrass y Allon White han estudiado las metáforas zoológicas del desprecio con las que la literatura de Occidente (sin excluir, desde luego, la marxista) ha cargado a lo largo de los siglos a los pobres, marginales, mendigos, desarrapados y lúmpenes a los que siempre condenó. Las figuras son conocidas: cerdos, ratas, cucarachas... Son las figuras con las que se habla, con much a frecuencia, de los hombres y mujeres que sobran en una sociedad, y no es difícil ver la relación entre las condiciones que permiten su uso y lo vuelven verosímil y la presencia efectiva de esos animales (ya hablamos de los cerdos $y$ de sus criadores; Suárez alude también a los "roedores e insectos" que habitan los basurales) en medio de los restos y de los desechos de la ciudad. Habría mucho, sin duda, para conversar sobre estas contigüidades entre hombres, o animales ( $\mathrm{u}$ hombres a los que se nombra con el nombre de animales: "es una rata", "son unas cucarachas”), y basura. Contigüidades vitales, como las de los recuperadores o los criadores de animales que se alimentan en los basurales, o mortales, como la de los fusilados de José León Suárez o las de las mujeres (Ángeles Rawson, Paula Jiménez) asesinadas y arrojadas muertas en medio de los despojos.

De los tres ejemplos que, un poco a la ligera, acabo de proponer (el de los cerdos, el de las ratas y el de las cucarachas), el primero me parece el menos sugerente.
La metáfora del cerdo ha tenido una larga militancia en la historia del desprecio de los otros, en la que ha ocupado más bien el lugar o la función de la indicación de la holganza, la pereza y el estar comiendo y engordando todo el tiempo. Marx hablaba de "cerdos burgueses", figura por muchas razones sugerente, pero no en el contexto en que estamos planteando estas consideraciones. En cambio, las figuras de las cucarachas y de las ratas nos importan mucho acá. Porque son animales repugnantes, porque son animales que es casi imposible pensar si no es integrando conjuntos muy numerosos, porque son animales que siempre están asediándonos, que siempre están volviendo sobre nosotros, porque son plagas. Ignoro cuánto hay de cierto en el mito urbano según el cual en Buenos Aires hay siete ratas por cada ser humano. Pero el caso es que ese mito funciona y hace de esas ratas que, en un número enorme, inquietante, temible, están ahí, siempre, como acechando, algo muy parecido a lo que aquí hemos pensado bajo los auspicios de la figura del espectro. Ignoro si es verdad que las cucarachas son los únicos animales que sobrevivieron a la bomba de Hiroshima. Pero el caso es que no hay manera de que no estén siempre volviendo, de cualquier montón de mugre o de basura, de la muerte a la que en vano quieren condenarlas nuestras impotentes campañas públicas o privadas de exterminio.

\section{IV}

Restos y desechos. En nuestro lenguaje cotidiano, las dos palabras funcionan casi como sinónimos, nombran las sobras de lo que consumimos, la basura con la que no sabemos bien qué hacer, y que tiramos, sin que el hecho de tirarla, desde luego, nos 
asegure que hemos resuelto el problema. En el lenguaje más técnico del psicoanálisis, son categorías que cargan una cantidad de significados y de cuestiones de lo más interesantes, que excedería mis posibilidades y mi competencia no ya tratar, sino incluso puntear acá con mínima solvencia, pero sobre los que estoy seguro que un análisis más cuidadoso podría arrojar enseñanzas importantes para el análisis político y social. En este último campo, al que sugerí tratar de aproximarnos a partir del recurso a los géneros clásicos de la tragedia y la comedia, tengo la impresión de que las dos categorías pueden ayudarnos mucho. El notable libro de Suárez que hemos considerado en el apartado anterior nos ofrece alguna clave adicional para aproximarnos a esta cuestión, que nos ayuda a pensar por la vía de un conjunto de desplazamientos metonímicos y de recursos metafóricos de lo más interesantes en torno a la cuestión de los residuos. Bien vistas las cosas, lo que Suárez nos muestra es que esta cuestión, que querríamos poder pensar como, ella misma, residual en relación con los grandes temas de la vida colectiva, está en realidad en el centro de todos ellos.

\section{REFERENCIAS BIBLIOGRÁFICAS:}

Derrida, J. (I993), Spectres de Marx. L'État de la dette, le travail du deuil et la nouvelle Internationale. París, Galilée.

Freud, S. ( I990), El malestar en la cultura en Obras Completas (Vol. 21) Buenos Aires, Amorrortu.

LACAN, J. (I983), "Hamlet, un caso clínico", en Lacan oral. Buenos Aires, Xavier Bóveda.

Laclau, E. y Mouffe, C. (I987), Hegemonía y estrategia socialista. Hacia una democracia radicalizada. Madrid, Siglo XXI.

Marx, C. (I885), El Dieciocho Brumario de Luis Bonaparte. Moscú, Progreso. (1873), El Capital. México, Siglo XXI.

Rancière, J. ( I996), El desacuerdo. Política y filosofía. Buenos Aires, Nueva Visión.

Rinesi, E. (2003), Politica y tragedia. Hamlet, entre Maquiavelo y Hobbes. Buenos Aires, Colihue. (2009), Las máscaras de Jano. Notas sobre el drama de la historia. Buenos Aires, Gorla.

(2013), Muñecas rusas. Tres lecciones sobre la república el pueblo y la necesaria falla de todas las cosas. Buenos Aires, Las cuarenta. (2016), Actores y soldados. Cinco ensayos hamletianos. Los Polvorines, UNGS.

Sasturain, J. (2016), "Corregime”, en El versero. Cien poemas (I976-2016). Buenos Aires, Gárgola. 
Shakespeare, W. (I985), Hamlet (ed.: P. Edwards), Cambridge, CUP. (I987), The Merchant of Venice

(ed.: M. M. Mahood), Cambridge, CUP.

Stallybrass, P. y White, A. (I986), The politics \& poetics of transgression. Cambridge, Cornell University Press.

SuÁrez, F. (2016), La Reina del Plata. Buenos Aires: sociedad y residuos. Los Polvorines, UNGS.

Walsh, R. (I957), Operación masacre. Buenos Aires, Sigla.

\section{RESEÑA CURRICULAR DEL AUTOR}

Dr. Eduardo Rinesi es politólogo y filósofo, investiga y enseña en la Universidad Nacional de General Sarmiento, donde se desempeñó como director del Instituto del Desarrollo Humano entre 2003 y 2010 , y como rector entre 2010 y 2014 , y donde actualmente dirige la Carrera de Especialización en Filosofía Política. 